BULGARIAN ACADEMY OF SCIENCES

CYBERNETICS AND INFORMATION TECHNOLOGIES • Volume 15, No 3

Sofia $\bullet 2015$

Print ISSN: 1311-9702; Online ISSN: 1314-4081

DOI: $10.1515 /$ cait-2015-0045

\title{
Trends and Opportunities in Computer Science OER Development
}

\author{
Christo Dichev ${ }^{1}$, Darina Dicheva ${ }^{1}$, Gennady Agre ${ }^{2}$, Galia Angelova ${ }^{2}$ \\ ${ }^{1}$ Winston Salem State University, Winston Salem, NC, USA \\ ${ }^{2}$ Institute of Information and Communication Technologies, 1113 Sofia \\ Emails: \{dichevc,dichevad\}@wssu.edu_agre@iinf.bas.bg galia@lmlbas.bg
}

Abstract: The world is embracing an open education model. The success of this process implies an adequate awareness, an assumption that is inconsistent with recent reports and statistical facts. Despite the major advances in recent years, Open Educational Resources (OER) are still not in the mainstream of Computer Science course development. Motivated by the need to fill this gap, this paper analyzes the evolution of the OER development and the emerging trends relevant to Computer Science education. The aim is to raise the awareness and promote a practical transition process towards an adequate model that aligns the interests of all stakeholders.

Keywords: Open education, Open Educational Resources, Computer Science education.

\section{Introduction}

The Open Educational Resources (OER) movement began in 2001 when the Hewlett and Mellon foundations jointly funded MIT's OpenCourseWare (OCW) initiative. OER are freely accessible, openly licensed documents and media that are useful for teaching, learning, and educational, assessment and research purposes (https://www.wikipedia.org/). Open content is often interpreted as meeting the "5R's": retain, reuse, revise, remix, and redistribute [1]. The development of OER is driven by a desire to provide an alternative educational paradigm and limit the commercialization of knowledge.

Much of the motivation for this paper came from the results of Babson/Pearson survey [2], which aimed at assessing the awareness about and adoption of OER. According to the survey, almost three-quarters of the college faculty were unaware of OER (2/3 were unaware in general and 3/4 were unaware when using a stricter definition of the licensing). The outcomes of the Babson survey are consistent with reports of earlier surveys conducted with higher 
education faculty and students [3]. Although these findings are disappointing, they reveal missed opportunities. In particular, they reveal the existing potential for a much wider adoption of OER. An obvious way for exploiting this potential is to increase the faculty awareness about OER. The pertinent question here is: how and which bodies can take the initiative to promote OER among the unaware faculty and students? This question becomes even more significant when taking into account that there are over 500 million openly licensed educational resources [4]. OER are out there somewhere, but how to bring them on campus?

The success of embracing an open education model implies an adequate awareness. While different aspects of OER adoption have been widely reported, little is known about the state of the art, the advancement, the emerging trends, as well as the actual impact of OER across different disciplines, from the viewpoint of the stakeholders. Even less is known about what kind of open resources are available compared to what is used and needed. For example, the information about the type, scope, target groups and driving forces in the evolution of Computer Science (CS) OER is very limited. The need to raise the awareness about OER stimulated us to use the information about the CS OER gathered in the process of populating and maintaining the CS OER Portal [5] and the Computing Ensemble Portal (computingportal.org) for analyzing the current state of affairs and tracking emerging trends and barriers in this area. Making parallels with the Open Source Software (OSS) community, we believe that the CS Education (CSE) community is the relevant forum for discussions about the role of OER in CS education. The intention is to make CS OER better known, understood and utilized.

Despite some significant advances in recent years, OER is not a routine part of CS course development yet. The SIGCSE conferences (http://www.sigcse.org/events/symposia) support this observation: the significant number of papers on teaching experiences is in sharp contrast with the limited number of open related resources demonstrating them. The academic nature implies sharing knowledge and building upon ideas of others. OER provide a unique opportunity to expand the research traditions of building on the ideas of others into teaching practice. Our observations, however, demonstrate that educational research does not connect well with the open education practice [6]. These observations are even more pertinent in the light of the following three facets of CS education which would benefit from CS OER production.

Computer Science discipline. Computer Science is dynamic. It evolves and experiences transformation continuously. Open teaching materials, covering emerging fields can help instructors and students unfamiliar with particular topics. CS graduates spend a significant part of their career in self-learning. Providing OER can help them stay current and grow along with their chosen profession.

Computer Science career. Parallel demands come from employers. The workforce demands skills from college graduates that have to be acquired from informal learning experiences [7]. OER would enable them to learn new required skills or explore a new subject.

Computer Science Open Source Community (OSC). OER and OSS are similar in that both rely on sharing open assets and licenses that allow the use, modification 
and redistribution of assets. Giving away the ideas and source code is the base for the activities in the OSC, which also becomes vital for the creation of culture. OSC (mostly CS graduates) give away ideas and a source code in return for status and reputation. Similarly, by giving away the knowledge instructors can gain recognition and reputation and build up an OER culture.

Despite the presence of conditions promoting OER production, Computer Science does not stand out from the rest of the disciplines. The inadequate popularity of CS OER is a signal for the need of a suitable model that aligns the interests of all stakeholders. Iterating toward an adequate model, OER evolved in several dimensions and took several forms. The next section explores the OER evolution, the challenges and opportunities entailed by the different approaches.

\section{Patterns in OER development}

OER are released under an intellectual property license that permits their free use or redistribution. They include learning content (full courses, course materials, content modules, learning objects, collections, and journals), tools (platforms for hosting courseware or open textbooks, online learning platforms or open learning management systems) and implementation resources (intellectual property licenses, design-principles, etc.). The term OER was later broadened to "open education" (OE), which is the term used in the Cape Town Open Education Declaration [8]. Based on the major initiatives, OER can be grouped in the following categories: open courseware, open textbooks and open online courses.

Open courseware. Open CourseWare $(\mathrm{OCW})$ is course material on a specific subject that is made freely available [9]. Examples include lecture notes, readings, course assignments, syllabi, problem sets, exams, illustrations and videos. Typically they are aligned to a particular syllabus and requirements, but can be customized to meet the individual needs. Large universities often make some of their course materials available as $\mathrm{OCW}$.

OCW gives teachers a set of educational templates with which to build their own courses and improve pedagogy. Learners can use courseware to guide their studies or keep their knowledge current. The main missing ingredient of the OCW experience is the social element of the classroom. The following are several wellknown projects illustrating different OCW approaches, models and scales.

MIT OpenCourseWare (ocw.mit.edu) is the best-known example of open courseware and it is the most copied institutional OER model providing course materials used in MIT classroom teaching. MIT's OpenCourseWare is noteworthy in its scale, completeness, quality and positive influence on others.

The Carnegie Mellon Open Learning Initiative (OLI) (oli.cmu.edu) is an online learning environment that might constitute an alternative to traditional classroom teaching by promoting greater student-content interaction and more frequent feedback on their performance and understanding. The design of OLI courses has been guided by cognitive principles of learning.

The OpenLearn initiative (www.open.edu/openlearn/) was launched by the UK Open University to make a selection of materials available for free and to build 
communities of learners/educators around the content. OpenLearn complements the MIT OCW by providing not only a collection of free course materials, but also a set of tools to help authors publish and support collaborative learning communities.

OpenMichigan (open.umich.edu) offers the University of Michigan course materials, software and student work for free allowing users to explore, build and redistribute educational content.

Japan OpenCourseWare Consortium (JOCW) (www.jocw.jp) offers around 400 courses created by 19 member universities. They include lecture notes, syllabi, readings, assignments, exams and video or audio lectures.

Open textbooks. Amid the efforts to make education affordable, there is one holdout: textbooks. The college textbooks are so expensive that $65 \%$ of students report not buying a required textbook [10]. Open textbooks have a number of advantages over traditional textbooks. Above all, they are free and openly available. Open textbooks can be delivered in different formats, including text, images, audio, video and other multimedia versions [11]. Revisions and updates can be made efficiently online. In particular, open textbooks allow catering for learning differences - instructors may customize the textbooks to fit specific teaching and learning needs. They are a logical consequence of the developments in OER and OCW. Open textbooks are developed by digital publishers that make them available to individuals and schools for free or comparably low prices. Organizations, such as Flat World Knowledge (http://www1.flatworldknowledge.com/), Panopen (https://panopen.panopen.com/), and OpenStax (http://openstax.org/), are using OER to develop free and low-cost textbooks. The following are some examples:

College Open Textbooks (collegeopentextbooks.org). This collection of sixteen educational organizations, affiliated with more than 200 colleges, is focused on driving awareness and adoptions of open textbooks to more than 2000 community or two-year colleges. It includes providing training for instructors adopting open resources, peer reviews of open textbooks, mentoring online networks that support authors opening their resources and other services.

Flat World Knowledge (catalog.flatworldknowledge.com). This publisher provides high-quality, affordable college textbooks and an online platform that allows instructors to personalize the content. The company revolutionized the creation of college textbooks, using technology to efficiently deliver content to more than 1 million students, 13,000 faculty and 2,500 institutions worldwide.

OpenStax (openstaxcollege.org). This nonprofit organization offers free textbooks that meet the scope and sequence requirements for most introductory courses in the selected areas. The textbooks are written by professional content developers and peer-reviewed. Currently OpenStax offers nine introductory texts used by about 140,000 students at more than 850 institutions.

Open online courses. Open online courses are an evolutionary outgrowth of two major trends: the OER movement and online learning, with its technological and pedagogical experiments (e.g., flipped classrooms, use of multimedia), and assessment. As such, they are usually full courses with actual assignments and a similar structure to a traditional college class and allow interactive participation, 
including interactions between instructors and students. They are typically free courses, without formal entry requirements nor participation limit. Although they include interaction, feedback and assessment (via automated quizzes or peers), in general they do not lead to official credentials. At present, open online courses are largely university-level courses.

Massively Open Online Courses (MOOCs) are open online courses with large (massive) enrolment. The first MOOC - Connectivist Knowledge, offered by the University of Manitoba in 2008 - took its inspiration from OER and connectivism, using many platforms to ensure that devices were not a limitation to participation. This course had an enrolment of about 2,200 students [12] (not as large as later MOOCs). For its creators, however, the size was of less importance than the use of a creative pedagogy built around the principles of connectivism, autonomy, diversity and interactivity.

The first massive courses that captured the imagination of people outside education were three courses offered by Stanford University in 2011. Each had enrolments of over 100,000 students, and in one class on Artificial Intelligence, enrolments approached 160,000 students [13]. Among other positive changes, MOOCs may strengthen the sustainability and use of OER, educate millions worldwide, increase the visibility of new ideas and form collaborative learning spaces where students work together. The following are some examples of leading MOOC providers that are setting the standards and illustrate various ways for MOOCs to be incorporated into educational/training settings.

Udacity (https://www.udacity.com/). Founded in 2011, Udacity was the first major provider of MOOCs. It continues to be a front-runner in free online education and learning technology in particular. While other MOOC providers have branched out into liberal arts and other subjects, Udacity remains focused on Science, Technology, Engineering and Math (STEM), particularly Computer Science. Unlike other MOOCs, Udacity courses are self-paced, allowing students to take classes at their convenience. It has also partnered with universities to offer credit for courses completed through the system [14].

Coursera (https://www.coursera.org/). With more than 500 courses from over 97 universities worldwide and more than 5 million learners, Coursera is the largest organization offering MOOCs today. These massive offerings have made Coursera one of the most highly used MOOC sites. Coursera has solved one of the major criticisms of MOOCs: verifying that a student has actually completed coursework. Using "Signature Track", students can link coursework to their identity and earn a verified certificate that is officially recognized by employers and universities. Like Udacity, Coursera has taken steps to offer courses with college credit to their students [14].

EdX (https://www.edx.org/). A joint effort of MIT and Harvard, edX is one of the leaders in the MOOC movement. Its focus is on high-quality educational content, offering courses from legendary professors. Like Udacity and Coursera, edX offers certificates for most of its courses. But edX is the first one with a series certificate, XSeries. Students can earn an XSeries Certificate by completing and passing a series of courses in a specific subject [14]. The edX consortium currently 
comprises 28 universities. It has collaborated with Stanford University on platform development, and has released OpenEdX (http://online.stanford.edu/openedx) as an open source platform.

OpenUpEd (http://www.openuped.eu/). Launched in April 2013, OpenUpEd is the first Pan-European MOOC initiative, with support of the European commission [14]. It includes partners from 11 countries and has multilingual courses, which is a bonus for reaching a broader learner audience. OpenUpEd has been initiated and is coordinated by the European Association of Distance Teaching Universities.

Open tools and OSS as a platform and as a model. OER include also tools to develop, use and distribute the content [15]. In this aspect, OSS plays a dual role: as a platform for building tools and as a model for guiding OER development. Tools allow content downloading, configuration and customization, as well as publishing, use, evaluation or adaption of resources. The examples are platforms for open online courses and for hosting open textbooks, courseware and OER repositories. The OER principles were inspired by the OSS movement. For example, the OSS development model was used to guide the design of Connexions (cnx.org), a platform for creating, storing, remixing and sharing peer-produced modular learning content.

Implementation resources. Implementation resources refer to intellectual property, design-principles, and localization of content [15]. The licensing options as defined by Creative Commons (creativecommons.org) enable the sharing and use of knowledge through free legal tools. There are four types of Creative Commons licenses distinguished by the following features [11]:

- Attribution (BY). This allows users to copy, distribute and display the work and make derivative works, as long as the author is given the credits for the original creation.

- Share-Alike (SA). This allows users to distribute derivative works only under a license identical to the license that governs the original work.

- Non-Commercial (NC). This allows users to copy, distribute, display the work and make derivative works based on it, only for noncommercial purposes.

- No Derivative work (ND). This allows users to copy, distribute and display the work, but not to make derivative works.

These features are combined in different ways to create six Creative Commons licenses, which define a spectrum of copyright permissions for creative work

\section{Facts and trends}

New target group. The concept of OER is evolving. For a long time, OER have been associated with formal education, the primary OER target group consisted of instructors, and the emphasis was on the reuse of educational resources. The growth of open online education and the arrival of MOOCs is shifting the focus towards students as the primary target group. This group consists not only of formal students but also of "self-learners". Personal development and employability are important motives. For example, more than $43 \%$ of the users of MIT OCW and $28 \%$ of Delft 
OCW belong to this category [16]. This shift offers higher education new opportunities: the new target groups located all over the world extend vastly the reach of open education.

Open courseware. Although studying OCW does not lead to receiving degrees or accessing faculty members, it helps spreading knowledge to people that otherwise do not have access to it. This is confirmed by recent statistics, reporting that there are currently over 100 million open courseware students [17]. The MIT evaluation [18] reports that $31 \%$ of OCW users used it to improve personal knowledge, $22 \%$ to learn a new teaching method, $20 \%$ to incorporate OCW materials into a course, $15 \%$ to find reference materials for students and $8 \%$ to develop curricula. In this direction, mobile devices and apps are steadily becoming accelerators for OER (e.g., Khan Academy, iTunes U). In terms of using OER, an interesting project is undertaken at CUNY's Office of Library Services [19]. The goal is to develop and test a model of training and incentivizing faculty to identify, adapt and adopt OER and deploy them in classroom settings. The project plans to pilot OER in 50 courses. Similarly, the University of Massachusetts-Amherst, in seeking out cheaper alternatives, launched a pilot program for faculty to redesign their courses using only OER [19]. The reported results for 44 courses and $\$ 39,000$ invested, amount to over $\$ 1$ million in savings for more than 5,000 students.

Social aspects. The OER approach was generally content-driven, with little attention paid to social aspects [20]. An emerging tendency is to embed social dimension in OER repositories [21], which can facilitate collaborative learning. A recent example is Mookia (mookia.com), an evolving platform aimed to enrich the OER systems with social learning. Mookia allows users to interact with each other. Three top-level objects: courses, groups and profiles create social spaces for learners to collaborate.

Open textbooks The main argument for promoting OER is improving the quality and cutting costs in education. Recent studies have shown that open textbooks are a more efficient learning solution compared to the conventional options [45]. However, the Babson survey [2] revealed that, although open textbooks can significantly reduce the cost, instructors consider cost in the least important criteria. This fact is even more disturbing considering that there is no built-in resistance to OER adoption by faculty compared to other technology-driven educational initiatives [2]. (For comparison, the faculty acceptance of online education is only $30 \%$ [22]). An emerging business model is the compilation of textbooks from OER and offering them free in a digital format and printed copies at a low price. The profit is distributed to the company for providing the service and the authors for compiling the content and supporting materials. An example is the OpenStax College.

MOOCs. MOOCs are being widely explored as alternatives and supplements to traditional university courses. In particular, MOOCs have forced the OER movement to re-evaluate itself in terms of how it fits in to the modern education landscape. There is also an expectation that MOOCs could contribute to improving the quality and cost-effectiveness of higher education and to broadening and innovating learning. Another promise is that MOOCs would allow a better 
articulation between higher education and the labor market, and would provide professional education opportunities for learners outside universities [23]. While teaching with OER or open textbooks is being neglected by a large percentage of instructors, MOOCs are appealing to them; $91 \%$ of the instructors teaching MOOCs plan to continue or increase their participation [24]. MOOCs have been endorsed by the educational administration, too. For example, the American Council on Education assessed five MOOCs in early 2013 and issued a recommendation to its members to accept the Signature Track certificates in exchange for credits [25]. But most notably MOOCs are appealing to masses. In one year the unique registered users have grown from 3.6 million to $9.7+$ million. The number of MOOC courses went from 200+ in 2012 up to 1,000+ in 2013 up to 1,533 by February 2014 [26].

\subsection{Computer Science OER production}

From an institutional perspective, the interest in OER and specifically CS OER is lower compared to MOOCs. From 22,123 universities around the world (http://www.webometrics.info/en/node/54) only 46 include Computer Science resources in their OER repositories [27]. According to the U.S. Department of Education (http://nces.ed.gov/fastfacts/display.asp?id=84) the total number of the US four year universities was 2,870 in 2011. From these, 19 universities are offering OER (https://www.oercommons.org/oer/providers), which is about $0.7 \%$ of the total number. A closer look reveals that only six universities actually offer CS resources, while the total number of universities offering CS degree is 787 (which is again about $0.6 \%$ of the total number of universities offering CS degree). The development of OSS can be considered as a form of online knowledge sharing. According to Lerner and Tirole [28], about 2.1 million US citizens had a computer science job at the beginning of this millennium. They also note that of the potential 2.1 million contributors to the open source community, about 13,000 people (or $0.62 \%$ ) actually contributed some code. Likewise according to a recent study [29] about $0.87 \%$ of the registered Wikipedians are considered active (contributing) users. Since our observations are consistent with the data from related open initiatives, it is perhaps unrealistic to expect that the number of the CS OER resources will grow significantly without extra energizing factors.

Although MOOCs are not strictly OER, they grew from OER roots and epitomize a move towards greater accessibility of higher education. Most notably, MOOCs have shown that when the educational resources are set within the right framework and embedded properly in the educational ecosystem, they have the capacity to change the way the content is produced and shared. Thus MOOCs provide CS educators with a vehicle to think creatively and explore new pedagogical practices, business models and learning paths in their provision.

\subsection{The impact of CS on OER evolution}

From open access to OER, and more recently, open online courses and MOOCs, there is growing momentum for the CSE community to participate in the open movement. The following facts are a manifestation of the role of this community in the process. 
The turning point in MOOCs was 2011, when Stanford CS professors offered three of the school's most popular CS courses as MOOCs - Machine Learning, Introduction to Artificial Intelligence and Introduction to Databases. The Introduction to AI (taught by Sebastian Thrun and Peter Norvig) was a really massive course attracting 160,000 students from over 190 countries. Coursera is also founded by Stanford CS professors, Andrew Ng and Daphne Koller [30]. Launched in April 2012 as an educational technology company offering MOOCs, by February 2013 Coursera had over 69 university partners offering courses in Chinese, Italian and Spanish. According to statistics compiled in 2013 [31] 27\% of the MOOC courses are in Computer Science. Similarly, science and technology MOOCs are the largest number of MOOCs in Europe [32]. More interesting is that Georgia Tech, Udacity, and AT\&T have teamed up to offer an online Master's degree in $\mathrm{CS}^{\sim}$ the first of its kind delivered through a MOOC. As an alternative, Coursera offers specializations (Data science, Android, Cyber Security and Fundamentals of Computing) [33] that allow students to follow university-led tracks and attain mastery in a particular subject.

On the major providers, the opportunity to teach MOOCs has been an inviteonly proposition to established universities and professors. But new platforms, such as OpenEdX and MOOC.org can make this more easily available. OpenEdX is the open-source release of edX, while MOOC.org is a partnership between open EdX and Google to create a MOOC authorship platform.

The quick rise in textbook prices has not been ignored by the CS educators. Allen Downey's "Think" series (http://greenteapress.com/) is one of the earliest examples of open textbooks [34]. Starting with introductory CS texts using Java and Python, it has grown to cover a large range of related topics. The positive attitude towards open textbooks is demonstrated by the fact that from total 811 open textbooks, 127 are CS textbooks (collegeopentextbooks.org).

Another dimension in the OER evolution is the collaborative development of educational content similar to OSS. While OSS relies on collaborative work, there are only two examples of OER that do rely on collaborative development: Wikieducator and Curriki. Several authors suggested the social code-sharing network GitHub as a tool for managing the OER production process. The idea is to use GitHub with open educational content as the "code" to share. Similarly to the OSS community model it will facilitate a culture of structured collaboration and improvement. A good example in this direction is Coursefork [35], a platform for open-sourcing and collaborating on courseware creation. It enables authors to upload course material, create copies, modify them and share the improvements. Coursefork's goal is to replace closed systems with open systems in the world of education.

Another evidence (developers.google.com/edu/curriculumsearch/) for the growing interests in OER and in particular in the CS OER is the Google Curriculum Search. A collaboration between Google and its academic partners, Curriculum Search helps users find teaching materials that have been published by faculty from CS departments around the world. Also, the OER Foundation has been selected as a mentor organization for this year's Google Summer of Code [36]. 


\section{Influences on OER growth}

Initially, our opinions and beliefs about OER formed are based on small scale case studies or surveys. We have lacked large data to justify these beliefs. The Babson survey [2] shows that almost three-quarters of faculty classified themselves as unaware of OER and fewer than 3\% rated cost as a significant factor in textbook selection. It is interesting to identify the causal factors behind that phenomenon in the light of the OER evolution.

The inadequate awareness of OER is a signal for some obstacles. Among the major obstacles to the OER growth are their dispersion and the need for adaptation to new contexts. As long as the effort for finding suitable resources is higher than the effort to create them, the OER potential for transforming educational practices cannot be fully realized. Neither institutional backing nor strong community attitudes will gain sustainable success [37].

Lack of formal incentives for educators to partake in the OER process is another negative factor. Few institutions or departments consider authoring OER in promotion and tenure decisions. As reported by [3], very few of instructors indicated creating open textbooks (7\%), open courseware (6\%) and OER (8\%) was considered as a criterion for promotion or tenure. The identification of a sustainable approach for the development of OER has proved elusive. The new trends in OER development are also motivated by the need to reach a sustainable model which assumes alignment of the economic and operational interests of all stakeholders faculty, administrators and students.

Other barriers [38] include lack of trust in the quality and relevance, and perception that each context is unique and it is too difficult to adapt the course content. The MOOCs' impact on education can partly be attributed to both: the reputation - most MOOCs come from world-class universities; and total educational experience - a MOOC provides a total package of OE at a course level, with learning resources and testing (with feedback) [39].

While the reasons for the slow uptake of OER are also valid for open textbooks, there are specific factors contributing to their low adoption rate. For the majority of instructors, the textbook is a convenient package without which the task of managing a class would be much more difficult. While instructors select textbooks for their students, they do not pay for them. Generally, instructors are not editors, let alone creators of their classroom content; they are simply end users. As such, a satisfying OER solution must require little work on the part of faculty [40]. The insufficient infrastructure for distribution and discoverability - how and in what form open textbooks are delivered - affects the adoption as well. Inertia both in individuals and institutions - is another barrier. It takes energy and commitment to change the way we do things [41]. The size of the pool of highquality materials ready for use also matters. While the current supply of open textbooks is expanding, they cover only a part of all college courses [42]. One not so obvious factor are the economic interests (of the publishers).

Paradoxically, OER are typically deployed in an LMS. There is a conflict between the openness of OER and the closed nature of the LMS [43]. For open 
content to reach its potential, the problems with adaptation and collaboration must be addressed. A Github for Education would address some of these challenges [44]. As we mentioned, an interesting development in this direction is undertaken by Coursefork, which is aimed at replacing the closed education systems with open ones using the GitHub model [35].

\section{Conclusion}

OER provide means to meet the growing demand for higher education by opening access in the form of OCW, open textbooks and open online courses. Such openness gives learners the freedom to personalize their own learning. Recently, the OER focus shifted from instructors to students. For self-learners, self-development and employability are the main reasons for using OER.

While there is an academic shift towards collaborative research, sharing CS teaching materials still lags behind. Since the learner's interest in open content continues to grow, the educators begin to support this trend. Driven by the increased demand for informal education and the wealth of CS OER and recently MOOCs, the learners are starting to experience a growing interest in accredited learning. Accordingly, several education providers are exploring avenues for accreditation or validation of skills and competences acquired through informal learning. Perhaps the value of OER will be realized when the learners begin to appropriate the materials freely available for designing their learning pathways and personalized content, and education providers find a way for formal recognition to this learning. In order for CS OER to deliver on its potential to improve the CS education, the sustainable business models, increased awareness, relevant policies and accreditation systems are among the key issues to be overcome. Developments and trends in CS OER mirror advances are occurring within OER in general. As OER and its derivatives are still in the early stages of development, further research is needed on issues, such as barriers, practices and business models to expand their opportunities.

Acknowledgment: This work was partially supported by the Project "AComIn: Advanced Computing for Innovation", Grant No 316087 funded by the European Commission in FP7 Capacity (2012-2016).

\section{References}

1. W i 1 e y, D. Open Content. http://opencontent.org/definition/.

2. B la i r, B. S. Faculty Survey Finds Awareness of Open Educational Resources Low. Babson College, 2014.

3. Florida Virtual Campus. Florida Student Textbook Survey. Tallahassee, FL, 2012. http://www.openaccesstextbooks.org/pdf/2012_Exec_Sum_Fac_Admin_OER_Survey. pdf

4. Recommendations to Save on Student Textbook Costs. The Ad Hoc Senate Committee on Student Textbook Savings. 2014 http://www.lib.utah.edu/pdf/TextbookSavingsReport_FINAL.pdf

5. Dicheva, D., C. Dichev. Finding Open Educational Resources in Computing. - In: ICALT'14, 2014, Athens, Greece. 
6. G e s e r, G. Open Educational Practices and Resources. Salzburg Research. EduMedia Group.

7. John s on, L., S. A. B e cker, M. Cummins, V. Estrada, A. Freeman, H. Ludgate. NMC Horizon Report: Higher Education Edition. Austin, Texas, The New Media Consortium, 2013. http://www.nmc.org/horizon-project

8. Muld e r, F., B. J a n s s e n. Opening up Education. - In: Trend Report OER. SURF SIG OER, Utrecht, 2013, pp. 36-42.

9. Abels on, H. The Creation of OpenCourseWare at MIT. - J. of Science Education and Technology, Vol. 17, 2007, No 2, pp. 164-174.

10. Faculty Like OER, When They Know About It, Degreed. http://degreed.com/blog/faculty-like-oer-know/

11. Che ung, S. K. S., K. C. Li, K. S. Y u e n. An Overview of Open Educational Resources for Higher Education. - In: Intl. Conference on ICT in Teaching and Learning, HKU Space, 2013.

12. D o w n e s, S. Access2OER: The CCK08 Solution, 16 February 2009. http://halfanhour.blogspot.ca/2009/02/access2oer-cck08-solution.html

13. P a p p a n o, L. The Year of the MOOC. New York Times, 2 November 2012.

14. Who Wants to Take College Courses for FREE? Leaders in the MOOC Movement, Affordable Degrees Online, 2014.

http://www.affordabledegreesonline.org/blog/who-wants-to-take-college-courses-forfree-leaders-in-the-mooc-movement/

15. OECD. Giving Knowledge for Free. The Emergence of Open Educational Resources. Paris, OECD Publishing, 2007.

16. D i d d e r e n, W., P. S l o e p. OER and Informal Learning. - Trend Report Open Educational Resources, Amsterdam: Open Educational Resources Special Interest Group, Vol. 20, 2013, No 15.

17. A n s o n, A. Open Courseware Statistics [Infographic]. October 2011. http://ansonalex.com/infographics/open courseware-statistics-infographic/

18. Massachusetts Institute of Technology. Program Evaluation Findings Summary, 2011. http://ocw.mit.edu/about/site-statistics/11_Eval_Summary_112311_MITOCW.pdf

19. Ke n d r i c k, C. Testimony of University Dean Curtis Kendrick to NYC Council on Textbook Affordability. CUNY, Library News, September 2014.

20. M a r g a r y a n, A., A. L it t l e j o h n. Repositories and Communities at Cross Purposes: Issues in Sharing and Reuse of Digital Learning Resources. - JCAL, Vol. 24, 2007, No 4, pp. 333-347.

21. Fett e r, S., A. J. B e r l a n g a, P. S l o e p. Peer-Support and Open Educational Resources. In: A. L. P. Okada et al., Eds. Collaborative Learning 2.0: Open Educational Resources. Washington, DC, IGI Global Publishing, 2012.

22. S i m o n, H. Changing Course. 10 Years of Tracking Online Education [Infographic], Edcetera, April 2013.

http://edcetera.rafter.com/changing-course-10-years-of-tracking-online-educationinfographic/

23. G a e b e 1, M. MOOCs: Massive Open Online Courses. European University Association. January 2013.

http://www.eua.be/Libraries/Publication/EUA_Occasional_papers_MOOCs.sflb.ashx

24. A d a movica, L. To MOOC or Not to MOOC: Strategic Lessons from the Pioneers. Slide Share.

http://www.slideshare.net/InsideTrackCoaching/ace-insidetrackmoocstrategystudyinfo graphic-mooc

25. Verste 11 e, M., M. S c hre u d e r, H. J e 1 g e r hu is. Recognition of MOOCs in the Education Sector. - In: 2014 Open Education Trend Report: SURF's Open Education Special Interest Group, 2014.

26. MOOCs' Next Phase: Global System for Credential Recognition. MOOCs University. SlideShares. 2014.

http://www.slideshare.net/MOOCsUniversity/moocs-next-phase-global-central-systemfor-credential-recogntion 
27. Listing of University and Colleges Offering OER.

http://libguides.tcc.edu/content.php?pid=552069\&sid=4550325

28. Lerner, J., J. T irole. Some Simple Economics of Open Source. - Journal of Industrial Economics, Vol. 2, 2002, pp. 197-234.

29. W e b e r, S. The Success of Open Source. Cambridge, Mass., Harvard University Press, 2004.

30. Ka menetz, A. How Coursera, a Free Online Education Service, Will School Us All. Fast Company, August 2012.

http://www.fastcompany.com/3000042/how-coursera-free-online-education-service-willschool-us-all

31. K in g, W. J., M. N a n fi t o. MOOCs for the Rest of US: An Inside Higher Ed. Webinar. National Institute for Technology in Liberal Education.

32. European MOOCs Scoreboard Open Education Europa. http://www.openeducationeuropa.eu/en/european_scoreboard_moocs

33. http://blog.coursera.org/post/73994272513/coursera-specializations-focused-programs-in

34. S i m i a n, P. Prereqs - not MOOC-Wrecks! Hitting the Books. Class Central, October 2014. https://www.class-central.com/report/prereqs-mooc-wrecks-hitting-books/

35. H ibbets, J. Coursefork: A New Way to Collaborate on Open Education. Red Hat. September 2013.

http://opensource.com/education/13/9/coursefork-education-tool

36. Computer Science Students: Apply to Mentor with OER Foundation for Google Summer of Code. Bccampus, 2014.

bccampus.ca/2014/02/26/computer-science-students-apply-to-mentor-with-oerfoundation-for-google-summer-of-code/

37. R e m m e l e, B. Open Educational Resources - Anonymity vs. Specificity. - European Journal of Open and Distance Learning, 2006, No 2.

38. C l e m e n t s, K., J. M. P a w l o w s k i. User-Oriented Quality for OER: Understanding Teachers' Views on Re-Use, Quality, and Trust. - J. of Computer Assisted Learning, Vol. 28, 2012, No 1, pp. 4-14.

39. S chuw er, R., B. Jan s s e n, W. van Valkenburg. MOOCs: Trends and Opportunities for Higher Education.

40. J a c o b s, B. OER Beyond Voluntarism. Inside Higher Ed., 2014. https://www.insidehighered.com/views/2014/08/28/open-educational-resources-moveme nt-needs-move-beyond-voluntarism-essay

41. Fry d e n ber g, J., G. M a t k i n, D. L. C e n t e r. Open Textbooks: Why? What? How? When? Menlo Park, CA, The William and Flora Hewlett Foundation, 2007.

42. Fixing the Broken Textbook Market Report by U.S. PIRG Education Fund., January 2014. http://www.uspirg.org/sites/pirg/files/reports/NATIONAL\%20Fixing\%20Broken\%20T extbooks\%20Report1.pdf

43. Open Assembly Beta: OER Meets Web 2.0. blog.openasse mbly.com/2014/12/03/open-assembly-oer-meets-web-20/

44. Characteristics and Potential of Github for Education. Open Tapestry, 02/19/2013. blog.opentapestry.com/2013/02/19/characteristics-and-potential-of-github-foreducation/

45. R o b i n s o n, T. J., L. F i s c h e r, D. A. W i l e y, J. Hilto n. The Impact of Open Textbooks on Secondary Science Learning Outcomes. - Educational Researcher, Vol. 43, 2014, No 7, pp. 341-351. 